\title{
THE NATIONAL SCIENCE FOUNDATION PROGRAM FOR MATHEMATICAL SCIENCES
}

\author{
LEON W. COHEN ${ }^{1}$
}

The purpose of this note is to inform mathematicians of the variety of support for research and education available through the Program for Mathematical Sciences in the National Science Foundation. The mathematical content of the program is determined by the interests of the mathematicians themselves. The program has no specific mission but endeavors to respond to the needs of basic research, to the demand for an increase in the number of competent students, both undergraduate and graduate, and to the requirements of new mathematical methods in the sciences. Some of the ways in which the program has aided in the advance of mathematics are listed below. Suggestions for other methods are most welcome.

Support is normally provided by a grant to the college, university or other institution through which a proposal is submitted but grants directly to individuals are possible. Information as to the usual content of a proposal, which is to be formulated by the one or more mathematicians seeking support, is set out in a booklet, Grants for Scientific Research. This will be supplied upon request to the Program Director for Mathematical Sciences, National Science Foundation, Washington 25, D. C. There are no printed forms to be filled out. Proposals may be submitted at any time during the year.

The following list gives some of the items which have been covered by grants for the support of research.

1. For individual mathematicians as principal investigators

1.1 Supplemental salary during sabbatical leave

1.2 Salary during special leave for research

1.3 Salary up to $50 \%$ to reduce excessive teaching or administrative load during the academic year

1.4 Salary for summer research

1.5 Salary for research by professors emeriti

2. For collaboration with principal investigators

2.1 Salary for graduate students as research assistants

2.2 Salary for mathematicians with the doctorate as research associates

${ }^{1}$ Program Director for Mathematical Sciences. This note is not to be interpreted as a formal expression of Foundation policy. 
3. For the development of research in departments of mathematics

3.1 Salary for visiting research professors and lecturers

3.2 Support for seminars in one or more broad fields of mathematics

This may involve several principal investigators and combine several items in 1 and 2.

4. For auxiliary purposes

4.1 Travel related to research

4.2 Secretarial assistance, particularly for the preparation of manuscripts

4.3 Publication costs

4.4 Computation costs

4.5 Permanent equipment

5. For the applications of mathematics

5.1 Numerical methods for high speed computation

5.2 New mathematical models for application to the sciences and operations research

6. For research and education in undergraduate colleges

6.1 Experimental programs for accelerated courses leading to faculty-student research groups in the junior and senior years.

In formulating a proposal one or more of the items listed may enter according to the requirements of the principal investigators. In some cases, proposals budget no funds for salaries of principal investigators who are full professors. The National Science Board has adopted the policy of encouraging proposals for a period of at least two and not more than five years. It is clear, however, that proposals dealing with sabbatical leave will have a term of one year.

Item 6, Experimental Programs for Research and Education in Undergraduate Colleges, is represented by only a few grants in the history of the program. Proposals embodying ideas pertinent to the local institution will be considered with great interest.

In addition to the direct support of research, the program has sponsored a three-day Conference on the Theory of Numbers, a Conference on Mathematical Tables and a Survey of Research and Training in Applied Mathematics. There is currently under way a Survey of Research Potential and Training in the Mathematical Sciences. The results of Survey visits to about 60 departments of mathematics are now being analyzed and shortly a questionnaire will be distributed to about 3,000 mathematicians having the doctorate. It 
is hoped that a picture of the existing capabilities and future needs of mathematics in the graduate schools will emerge. Other directions which the Survey has planned to investigate are the undergraduate situation, nonacademic careers in mathematics and the publication of mathematical material.

An indication of the growth of the program is given in the following annual totals of research grants:

Year (ending June 30) Number of Grants

Total Dollars

1952

1

$\$ 19,300$

1953

19

85,200

1954

21

173,950

1955

48

562,400 